\title{
Lung Transplant Consideration: Anesthesiologist Perspective
}

\author{
Sandeep Kumar Kar ${ }^{1 *}$ and Pallav Mishra ${ }^{2}$ \\ Department of Cardiac Anesthesiology, Institute of Post Graduate Medical Education and Research, India
}

*Corresponding author: Sandeep Kumar Kar, Department of Cardiac Anesthesiology, Institute of Post Graduate Medical Education and Research, Kolkata, India.
Received Date: August 07, 2020

Published Date: October 21, 2020

\begin{abstract}
Lung transplant has seen a significant progress since 1963 till this era. Worldwide lung transplant indications have broadened with time. Alpha 1 antitrypsin deficiency used to be the most common reason for transplant but now conditions like idiopathic pulmonary fibrosis, Cystic fibrosis, Non Cystic fibrosis bronchiectasis, lymphangioleiomyomatosis have become leading indications towards lung transplant. Relaxation of donor selection criteria management protocol preserving and optimizing lung function with development ex vivo perfusion techniques to recondition suboptimal lung has improved lung transplantation success. Post-transplant survival still poses challenge as median survival stands low around five years.
\end{abstract}

Keywords: Lung transplant; Donor criteria; Ex vivo; Post-transplant

\section{Introduction}

Organ Transplantation in India under aegis of National Organization Tissue Transplantation Organization (NOTTO) setup under Directorate General of Health Services established to oversee all donation and transplantation activities. In this regard, the entire

Table 1: History of lung transplant.

\begin{tabular}{|c|c|c|c|c|c|}
\hline National Level & \multicolumn{5}{|c|}{ (NOTTO) } \\
\hline Regional Level (ROTTO) & PGIMER Chandigarh & KEM Hospital Mumbai & IPGME \& R Kolkata & RGGGH Chennai & Guwahati Medical College \\
\hline State Level (SOTTO) & & & & & \\
\hline
\end{tabular}

Table 2: Anesthesia for Lung Transplant.

\begin{tabular}{|c|c|}
\hline Vladmir P Demikhov & $1^{\text {st }}$ experimental lung transplant 1940 [1,2] \\
\hline James Hardy & $1^{\text {st }}$ human lung transplant attempted in 1963 [3] \\
\hline Bruce Reitz and Norman Shumway & $1^{\text {st }}$ successful combined heart lung transplant [4] \\
\hline Joel Cooper & Two successful human single lung transplants [6] \\
\hline Starnes and co-workers & $1^{\text {st }}$ living lobar donor lung transplant in child with cystic fibrosis [8]. \\
\hline
\end{tabular}

country is having the following setup at National, Regional and State Level (Table 1 \& 2). Lung transplant be considered for adults with chronic end stage lung disease meeting all of the following general criteria [5]. 
a. High $(>50 \%)$ risk of death from lung disease within 2 years if lung transplant is not performed.

b. High ( $>80 \%)$ likelihood of survival at least 90 days after lung transplant.

Table 3: Lung transplant is complex procedure consideration for transplant. c. High $(>80 \%)$ likelihood of five years posttransplant survival from a general medical perspective provided there is adequate graft junction (Table 3 ).

\begin{tabular}{|c|c|}
\hline Absolute Contraindication & Absolute Contraindication \\
\hline $\begin{array}{l}\text { 1. Recent Malignancy } \\
\text { 2. Untreatable significant dysfunction unless combined organ transplant } \\
\text { be done } \\
\text { 3. Uncorrected atherosclerotic disease with suspected or confirmed end } \\
\text { organ ischemia/dysfunction } \\
\text { 4. Acute Medical instability not limited to acute sepsis, liver failure, } \\
\text { myocardial infarction. } \\
\text { 5. Uncorrectable bleeding diathesis } \\
\text { 6. Chronic infection with highly, virulent, or resistant microbes poorly } \\
\text { controlled pre-transplant. } \\
\text { 7. Active tuberculosis infection. } \\
\text { 8. Significant chest wall/spinal deformity expected to cause severe } \\
\text { restriction after transplant. } \\
\text { 9. Class II/III obesity. } \\
\text { 10. Nonadherence to medical therapy or prolonged episodes of } \\
\text { nonadherence to medical therapy. } \\
\text { 11. Psychiatric/psychological condition associated with inability to } \\
\text { cooperate with medical/ allied health care team. } \\
\text { 12. Absence of adequate social support. } \\
\text { 13. Severely limited functional status with poor rehabilitation potential. } \\
\text { 14. Substance abuse of dependence (alcohol, tobacco, marijuana). }\end{array}$ & $\begin{array}{l}\text { 1. Age> } 65 \text { years, low physiological reserve. } \\
\text { 2. Class I obesity. } \\
\text { 3. Progressive/severe malnutrition. } \\
\text { 4. Severe symptomatic osteoporosis. } \\
\text { 5. Extensive prior chest surgery with lung resection. } \\
\text { 6. Mechanical ventilation or Extracorporeal life support. } \\
\text { 7. Colonization or infection with highly resistant or virulent bacteria, } \\
\text { fungi, Mycobacterium bacilli. } \\
\text { 8. Infection with Hepatitis B, C consider transplant without significant } \\
\text { clinical, radiological, or biochemical signs of cirrhosis/Portal hypertension } \\
\text { stable on therapy. } \\
\text { 9. HIV, lung transplant for ones with controlled disease undetectable HIV } \\
\text { RNA compliant on combined ART therapy. } \\
\text { 10. Infection with Burkholderia gladioli, cenocepacia and multidrug } \\
\text { resistant Mycobacterium abscesses if infection treated preoperatively and } \\
\text { reasonable control postoperatively. } \\
\text { 11. Atherosclerotic disease burden sufficient to cause end organ disease } \\
\text { after lung transplant. Consideration to PCI/CABG and transplant. } \\
\text { 12. Medical condition be optimized like Type2 Diabetes Mellitus, } \\
\text { Hypertension, Epilepsy, Central venous obstruction, Gastroesophageal } \\
\text { reflux disease. }\end{array}$ \\
\hline
\end{tabular}

Table 4: Factors as per lung allocation score also highlight waitlist and transplant survival.

\begin{tabular}{|c|c|}
\hline Waitlist survival & Transplant survival \\
\hline Forced vital capacity & Forced Vital Capacity (B, D) \\
\hline Pulmonary artery diastolic pressure (A, C, D) & Pulmonary capillary wedge pressure(D) \\
\hline Oxygen requirement at rest (A, C, D) & Mechanical ventilation \\
\hline Age & Age \\
\hline Body Mass Index & Functional Status of patient \\
\hline T2 Diabetes Mellitus Insulin dependent & Diagnosis \\
\hline 6 Minute Walk test & \\
\hline Mechanical ventilation & \\
\hline Diagnosis by group (A, B, C, D) & \\
\hline
\end{tabular}

\section{Diseases Specific Candidate Selection}

Patient selection needs to be meticulous use of Lung allocation Score since 2005 prioritizes patients on the basis of risk of death on waiting list(urgency) and chance of surviving one year after transplant(utility) [7].

\section{Interstitial Lung Disease}

\section{Timing of referral}

Histological/radiographic evidence of Usual Interstitial Pneumonitis (UIP) or fibrosing Non-specific Interstitial Pneumonitis (NSIP) regardless of lung function.

Abnormal lung function

I. $\quad \mathrm{FVC}<80 \%$ predicted

II. DLCO $<40 \%$ predicted
Dyspnea/functional limitation attributable to lung disease. Oxygen requirement even if only during exertion. Interstitial lung disease with failure to improve dyspnea.

\section{Timing of listing}

Decline in FVC $>10 \%$ during 6 months follow up. Decline in DLCO $>15 \%$ during 6 months follow up. Desaturation $<88 \%$ or distance $<250 \mathrm{~m}$ on 6 minute walk test or $>50 \mathrm{~m}$ decline over 6 months. Pulmonary hypertension on right heart catheterization or 2D echo. Hospitalization because of respiratory decline, pneumothorax, or acute exacerbation.

\section{Cystic fibrosis}

\section{Timing for referral}

FEV1<_30\% with rapidly falling FEV1 despite optimal therapy. 
6 Minute walk distance $<400 \mathrm{~m}$

Pulmonary hypertension in absence of hypoxic exacerbation. Increased frequency of exacerbation associated with episode of acute respiratory failure requiring noninvasive ventilation Increasing antibiotic resistance and poor clinical recovery from exacerbation. Worsening nutritional status despite supplementation. Pneumothorax Life threatening hemoptysis despite bronchial embolization

\section{Timing for listing}

Chronic respiratory failure associated with hypoxia (PaO2<60mmHg/8kpa), hypercapnia PaCO2>50mmHg/6.6kpa) Long-term non-invasive ventilation, pulmonary hypertension frequent hospitalization, rapid decline in lung function and WHO functional class IV.

\section{COPD}

\section{Timing for referral}

Progressive disease despite maximal treatment including medication, oxygen therapy and pulmonary rehabilitation. Patient not candidate for endoscopic or surgical lung volume reduction surgery. Bode index 5 to 6 with presence of hypercapnia $\mathrm{PaCo} 2>50 \mathrm{mmHg} / 6.6 \mathrm{KPa}$ and hypoxia with $\mathrm{PaO} 2<60 \mathrm{mmHg} / 8 \mathrm{kPa}$ with associated FEV1 below 25\% of predicted value.

\section{Timing of listing (presence of one criteria is sufficient)}

BODE index $\geq 7$ or FEV1 $<15 \%$ to $20 \%$ predicted. Three or more severe exacerbation during preceding year. One severe exacerbation with acute hypercapnic respiratory failure. Moderate to severe pulmonary hypertension

\section{Pulmonary vascular disease}

\section{Timing of referral}

NYHA Class III/IV symptoms during escalating therapy, rapidly progressive disease, and parenteral targeted pulmonary hypertension therapy regardless of NYHA functional class. Known/ suspected pulmonary vaso-occlusive disease (PVOD) or pulmonary capillary hemangiomatosis.

\section{Timing for listing}

NYHA Class III/IV despite trial of 3 months of combination therapy including proteinoids. Cardiac Index below $2 \mathrm{~L} / \mathrm{min} / \mathrm{m} 2$ or mean right atrial pressure more than $15 \mathrm{mmHg}$. The six minute walk test less than $350 \mathrm{~m}$ and development of significant hemoptysis, pericardial effusion with signs of progressive right heart failure.

\section{Removal from waiting list}

Monitor patients for change in clinical status specially for Bridge to mechanical ventilation/Extracorporeal life support system. Presence of absolute/relative contraindications as listed above. Group A Mostly emphysema, Group B Pulmonary hypertension,
Idiopathic and congenital heart disease, Group C Septic lung disease like Cystic fibrosis, Group D Interstitial lung disease mostly Idiopathic pulmonary fibrosis (Table 4).

\section{Anesthetic Concerns}

Broad categories \& indications for lung transplant once satisfied requires thorough pre-operative assessment as highlighted by findings in timing and listing characteristics above.

\section{Pre-operative workup shall include [10-14]}

Preanesthetic workup covering patient disease history and physical examination along with latest pulmonary function test. Effort tolerance as assessed by six minute walk test or in case of exercise intolerance by Dobutamine stress echo. The latest transthoracic echocardiogram (2D) with or without right heart catheterization \pm coronary angiography depending on trans thoracic Echocardiography findings.

Antibiotic and immunosuppressant with possible need in selective cases for lung V/Q scan to assess lung tolerance for one lung ventilation.

\section{Premedication}

Preoperatively consideration to continuing the ongoing bronchodilator therapy, antibiotics and pulmonary vasodilator be considered. Patients on intravenous prostaglandins to continue till cardiopulmonary bypass (CPB) is initiated. Immunosuppression pre-transplant be considered as per institutional protocol. Sedation is avoided preoperatively as it can precipitate cardiorespiratory compromise. Post-operative analgesia by utilizing thoracic epidural analgesia or paravertebral block be decided preoperatively.

\section{Intraoperative Monitoring and Induction}

\section{Essential monitors}

Routine ASA standard intraoperative monitoring utilizing five lead electrocardiography system, pulse oximetry, quantitative waveform capnography, volatile anesthetic agent, core body temperature with invasive blood pressure, central venous pressure and consideration in presence of pre-existing pulmonary hypertension to pulmonary artery pressure pressure and transesophageal echocardiography monitoring be done alongside with the hourly urine output monitoring with indwelling Foley catheter and spirometric lung volume analysis be considered.

\section{Additional monitors as per institutional protocol can be}

BIS guided anesthetic depth, transcutaneous cerebral oximetry, near infra- red spectrophotometry, mixed venous blood oximetry, continuous cardiac output monitoring and continuous $\mathrm{ABG}$ monitoring

\section{Role of Tee [11]}

ASA/Society of Cardiovascular Anesthesiology Statement (2010) recommends TEE be used when planned surgery or patient 
cardiovascular pathology might result in severe hemodynamic, pulmonary, or neurologic compromise. Role of TEE in an End stage lung disease with Pulmonary artery hypertension due to lung pathology TEE evaluates during transplant [12-20] (Figure 1).

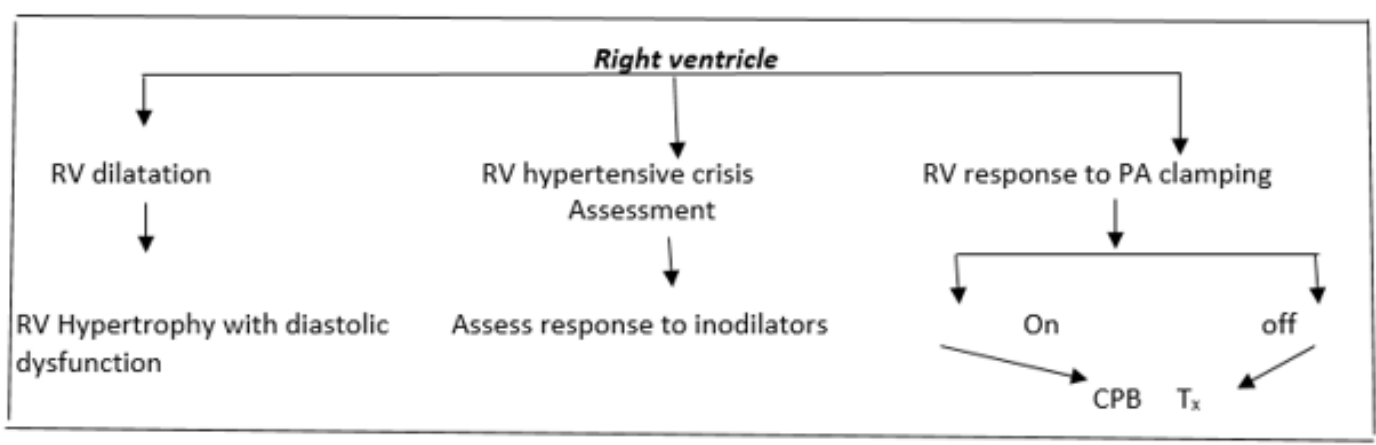

Figure 1

Preoperative screening for patent foramen ovale as it presents in $15-20 \%$ of patient population requiring intraoperative surgical closure [18]. Consideration for mechanical support requiring either cardiopulmonary bypass or ECMO [18]. Lung transplant candidates with suprasystemic pulmonary artery hypertension and gas exchange issues are ECMO supported preoperatively. Cannulation for ECMO can be guided by transesophageal echocardiography. Assessment for Pulmonary Venous Stenosis [19] with vessel diameter below $0.5 \mathrm{~cm}$, flow velocity more than $1 \mathrm{~m} / \mathrm{sec}$, left atrial to pulmonary vein pressure gradient more than 10 to $12 \mathrm{mmHg}$ are suggestive criteria for Pulmonary venous stenosis.

\section{Induction of Anesthesia}

Risk for cardio-respiratory collapse is high so surgeon/ perfusionist must be present for urgent sternotomy and cardiopulmonary bypass initiation. Hemodynamic goals are to preserve systemic vascular resistance and myocardial contractility, avoid increase in pulmonary vascular resistance by controlling factors like hypercarbia, pain, hypothermia, hypoxia, and hypovolemia. Narcotic based induction remains cornerstone involving $5-10 \mathrm{mcg} / \mathrm{kg}$ fentanyl with $0.05-0.1 \mathrm{mg} / \mathrm{kg}$ midazolam. Judicious dose of propofol followed by muscle relaxant and double lumen tube placed preferably left sided or single lumen tube for on pump single lung transplant can be considered. Double lumen tube provides increased surgical flexibility, irrigation of divided bronchus and differential ventilation after graft reperfusion with faster lung isolation.

\section{Anesthesia Concerns Specific to Disease $[5,17]$}

\section{Obstructive lung disease}

COPD/Alpha-one antitrypsin deficiency/ Bronchiolitis obliterans causative for smoking related emphysema entails preinduction arterial blood gas analysis. The risk of pneumothorax during positive pressure ventilation/central venous access be kept in mind. Dynamic hyperinflation and cardiovascular collapse can occur so expiratory time for ventilation be increased. The quantitative ETCO2 measurement can underestimate the PaCO2 due to increased alveolar dead space.

\section{Restrictive lung disease}

$\mathrm{IPF} /$ scleroderma/Drug or radiation induced lung disease can lead to high peak airway pressures requiring ICU ventilators in place of routine anesthesia ventilators as they may not be able to deliver sufficient flows. The risk for pulmonary hypertension is increased so risk of rising pulmonary vascular resistance.

\section{Suppurative lung disease}

Cystic Fibrosis/Non Cystic fibrosis bronchiectasis needs aggressive pulmonary toileting due to increased purulent alveolar secretions into large conducting airways. Risk of multidrug resistant infection be considered prior to surgery.

\section{Pulmonary vascular disease}

Pulmonary arterial hypertension candidate consideration to CVC/PA catheter prior to induction be considered due to high risk of hemodynamic instability. Pre-induction femoral cannulation for CPB be considered in high risk patients.

\section{Stages of Surgery}

a) Dissection of native lung

b) Donor lung anastomosis (Figure 2)

c) Graft Reperfusion

Deairing of graft through an opening in atrial anastomosis is done followed by lung inflation to sustained pressure of $15-20 \mathrm{cmH} 20$ with partial release of pulmonary artery clamp. Atrial clamp is decamped to de-air the cuff before final knot is tied. Look out for hypotension now (Figure 3) Management is small boluses of adrenaline/calcium.

\section{Coronary artery embolism}

Usual in RCA as its position is uppermost in supine position.PA clamp is released slowly over 10 minutes limiting initial graft flow has shown to reduce primary graft dysfunction. 


\section{Ventilation Strategy}

Maintain lowest fiO2 maintaining adequate oxygenation with low peak inspiratory pressure of $15-20 \mathrm{~cm} \mathrm{H} 20$ with PEEP $5 \mathrm{~cm}$ $\mathrm{H} 20$ and respiratory rate of $8-10$ breaths per minute.

\section{Complication}

\section{Primary graft dysfunction}

Graft removal leads to warm and cold ischemia with subsequent reperfusion injury leading to primary graft dysfunction [21,22]. Features of Primary graft dysfunction Poor oxygenation with severity graded-on basis of $\mathrm{PaO} 2 /$ fiO2 ratio. Poor respiratory compliance with high pulmonary vascular resistance and pulmonary edema.

\section{Management}

Lung protective ventilation strategy as per ARDS protocol Differentials synchronous lung ventilation if lung

compliance varies significantly. Selective pulmonary vasodilator Inhaled Nitric Oxide 10-40 ppm treat severe hypoxia and elevated pulmonary artery pressure (Figure $4 \& 5$ ).

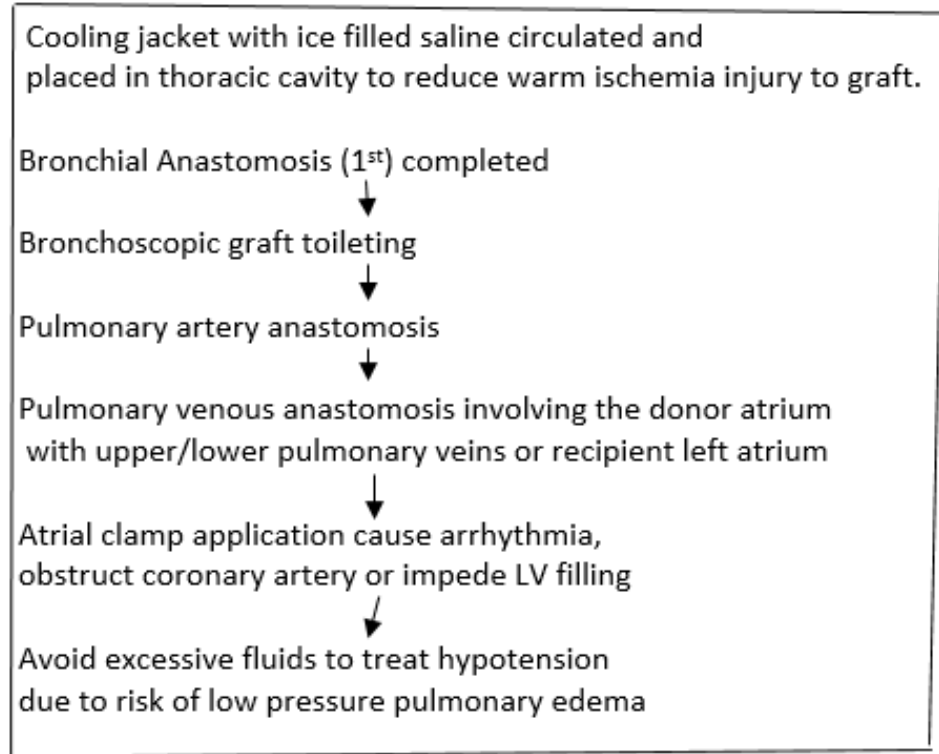

Figure 2

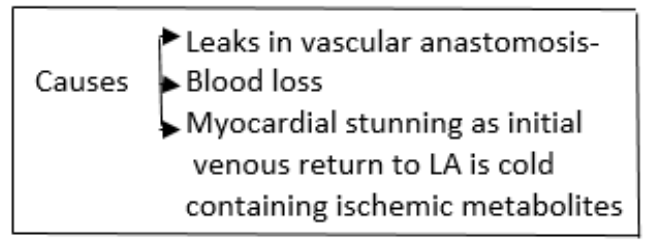

Figure 3

\section{Causes smooth muscle relaxation Reduced V/Q mismatch Reduced PA Pressure}




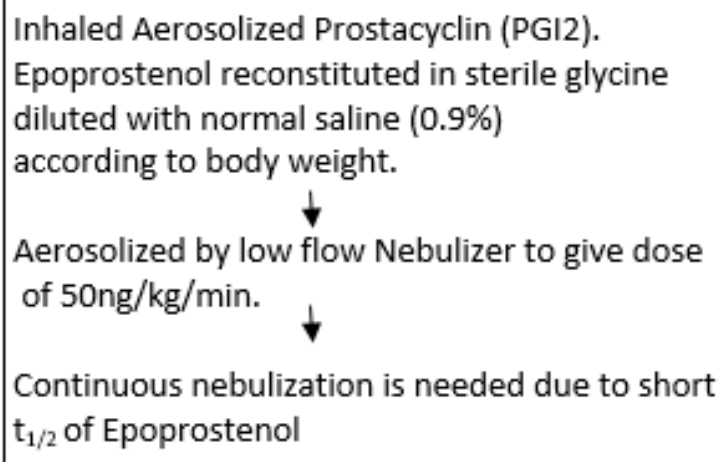

Figure 5: Prostaglandins.

\section{Acute Cellular Rejection [23-29]}

It occurs in upto $90 \%$ of patients in first postoperative year. It responds readily to simple augmentation of immunosuppressant with corticosteroids. Treatment reported in 40 to $50 \%$ patients during first year. Bronchoscopic transbronchial biopsy with histology showing perivascular and interstitial lymphocytic infiltrates. Based on the extent of lymphocytic infiltrates severity is grade. Reduced spirometry values measured at home can be used as standard daily monitoring Severe acute cellular rejection with increased incidence of bronchiolitis obliterans syndrome has clinical hallmark of chronic allograft rejection.

\section{Chronic Rejection of Lung allograft [24-33]}

Leading cause for long term morbidity mortality pathologically shows obliterative bronchiolitis. Clinically seen as progressive airflow obstruction associated dyspnea and cough. Augmentation immunosuppressants, lymphoid irradiation and photopheresis are effective treatment. Bronchiolitis obliterans syndrome is seen in $64 \%$ of post-transplant candidates with $20 \%$ drop in FEV1from baseline. Oral azithromycin recently has shown to improve lung function bronchiolitis obliterans syndrome.

\section{Infection [34]}

Transplanted lung is prone to various infections Bacterial, fungal, viral and parasitic as denervated lung with poor cough reflex and abnormal mucosal function limits removal of foreign material from Lungs. Maurer and colleagues found bacterial infection more common than viral and fungal infection [34].

\section{Airway compromise}

Donor bronchus depends on retrograde blood flow through low pressure pulmonary venous to bronchial vascular collaterals thus placing airway at risk of ischemic injury.

\section{Newer Development in lung transplant [35-37]}

Ex vivo perfusion system to condition lungs Hyperoncotic perfusate draws fluid out of extravascular space and causes dehydration of edematous lungs. Improved oxygenation permits successful lung transplant initially deemed unsuitable.

\section{Coupling Gene therapy technology}

In ex vivo technique Cypel and colleagues demonstrated that transfer of IL-10 gene to perfused lung improved oxygenation reduced pulmonary vascular resistance reduced proinflammatory cytokiene production with recovery of alveolar epithelial cell tight junction.

\section{Acknowledgement}

None.

\section{Conflict of Interest}

No conflict of interest.

\section{References}

1. Demikhov VP (1950) A new and simpler variant of heart-lung preparation of a warm-blooded animal. Bull Experimental Biology and Medicine 24: 383-390.

2. Cooper DK (1969) Transplantation of the heart and both lungs. I Historical review Thorax 24: 383-390.

3. Hardy KJ, Webb D, Dalton M, Walker GR Jr (1963) Lung homotransplantation in man. JAMA 186: 1065-1074.

4. Reitz BA, Wallwork JL, Hunt SA, Pennock JL, Billingham ME, et al. (1982) Heart-lung transplantation: successful therapy for patients with pulmonary vascular disease. N Engl J Med 306: 557-564.

5. David Weill, Christian Benden, Paul A Corris, John H Dark, R Duane Davis, et al. (2015) A consensus document for selection of lung transplant candidates: 2014 update from pulmonary transplantation council of the international society for heart and lung transplantation. J Heart Lung Transplant 34(1): 1-15.

6. Toronto Lung Transplant Group (1986) Unilateral lung transplantation for pulmonary fibrosis. N Engl J Med 314: 1140-1145.

7. Egan TM, Murray S, Bustami RT, Shearon TH, McCullough KP, et al. (2006) Development of the new lung allocation system in the United States. Am J Transplant 6: 1212-1227.

8. Cohen RG, Barr ML, Schenkel FA, DeMeester TR, Wells WJ, et al. (1994) Living-related donor lobectomy for bilateral lobar transplantation in patients with cystic fibrosis. Ann Thorac Surg 57: 1423-1427.

9. BA Reitz, JL Wallwork, SA Hunt, JL Pennock, ME Billingham, et al. (1982) Heart, lung transplantation successful therapy for patients with pulmonary vascular disease N Engl J Med 306: 557-564. 
10. Roscoe A (2011) Lung transplantation. In: Slinger P (eds.), Principles, and practice of anesthesia for thoracic surgery New York: Springer pp. 523-535.

11. American Society of Anaesthesiology and Society of cardiovascular Anaesthesiology at Task Force on Transesophageal echocardiography. Practice guidelines for perioperative Transesophageal Echocardiography (2010) Practice guidelines for perioperative transesophageal echocardiography. An updated report by the American Society of Anesthesiologists and the Society of Cardiovascular Anesthesiologists Task Force on Transesophageal Echocardiography 112: 1084-1096.

12. Saggar R, Lynch JP, Belperio JA, Weigt SS, Derhovanessian A, et al. (2010) Pulmonary arterial hypertension and lung transplantation. Seminar Respir CritCare Med pp. 147-160.

13. Kanagarajan N, Sankar NM, Nina Cherian KM (2004) Anaesthetic management and preservation of donor heart living for transplantation. Indian J Anaesth 48: 142-144.

14. Elumali RS, Somasundram G, Vaidyanathan K, VenkatramanR Nainar, Raghulan V (2013) Single lung transplantation in India An initialexperience. Indian J Chest Dis Allied Sci 55(2): 101-103.

15. Subramaniam K, Yared JP (2007) Management of pulmonary hypertension in operating rooms. Seminars in cardiothoracic and vascular anaesthesia 11: 119-136.

16. Di Tullio MR, Jin Z, Russ C (2013) Patent foremen ovale, subclinical cardiovascular disease and ischemic stroke in application based chart JAnn Cell Cardial 62: 35-41.

17. IP D, Slinger P (2011) Lung transplantation management during surgery. In: Klcin A (eds.), Organ transplantation a clinical guide Cambridge UK: Cambridge, University Press, Uk.

18. DeHoyos A, Demajo W, Snell G, Miller J, Winston T, et al. (1993) Preoperative prediction for use of cardiopulmonary bypass in lung transplantation. J Thoracic Cardiovasc Surg 106: 787-795.

19. Huang YC, Chen YJ, Lin YH, Wang Hx, Tsai SK (2000) Graft failure caused by pulmonary venous obstruction diagnosed by intraoperative Transesophageal echocardiography during lung transplantation. Anesthi Analog 91: 558-560.

20. Gorison J, Edwards TD, Ziady GM, Katz WE, Griffith BP (1995) Transesophageal echocardiography to evaluate patients with severe pulmonary hypertension for lung transplantation. Ann Thorac Surg 59: 717-722.

21. Christie JD, Carby M, Bag R, Corris P, Hertz M, et al. (2005) Report of the ISHLT Working Group on Primary Lung Graft Dysfunction part II: definition. A consensus statement of the International Society for Heart and Lung Transplantation. J Heart Lung Transplant 24: 1454-1459.

22. Christie JD, Bavaria JE, Palevsky HI, Litzky L, Blumenthal NP, et al. (1998) Primary graft failure following lung transplantation. Chest 114: 51-60.

23. Arcasoy SM (2004) Medical complications and management of lung transplant recipients. Respir Care Clin N Am 10: 505-529.
24. Bando K, Paradis IL, Komatsu K, Konishi H, Matsushima M, et al. (1995) Analysis of time-dependent risks for infection, rejection, and death after pulmonary transplantation. J Thorac Cardiovasc Surg 109: 49-57.

25. Trulock EP, Christie JD, Edwards LB, Boucek MM, Aurora P, et al. (2007) Registry of the International Society for Heart and Lung Transplantation: twenty fourth official adult lung and heart-lung transplantation report-2007. J Heart Lung Transplant 26: 782-795.

26. Otulana BA, Higenbottam T, Ferrari L, Scott J, Igboaka G, et al. (1990) The use of home spirometry in detecting acute lung rejection and infection following heart-lung transplantation. Chest 97: 353-357.

27. LeeJC, Jason D, Christic JD, primary graft dysfunction, proceedings of the American Therocic society 2001;6:39-46.

28. Mcllroy DR, Pilcher DV, Snell GI, (2009) Docs anaesthetic Management affect early outcome after lung transplant. An Exploratory Analysis BJA 102: 506-514.

29. Husain AN, Siddiqui MT, Holmes EW, Chandrasekhar AJ, McCabe M, et al. (1999) Analysis of risk factors for the development of bronchiolitis obliterans syndrome. Am J Respir Crit Care Med 159: 829- 833.

30. Heng D, Sharples LD, McNeil K, Stewart S, Wreghitt T, et al. (1998) Bronchiolitis obliterans syndrome: incidence, natural history, prognosis, and risk factors. J Heart Lung Transplant 17: 1255-1263.

31. Estenne M, Maurer JR, Boehler A, Egan JJ, Frost A, et al. (2002) Bronchiolitis obliterans syndrome 2001: an update of the diagnostic criteria. J Heart Lung Transplant 21: 297-310.

32. Estenne M, Hertz MI (2002) Bronchiolitis obliterans after human lung transplantation. Am J Respir Crit Care Med 166: 440-444.

33. Gerhardt SG, McDyer JF, Girgis RE, Conte JV, Yang SC, et al. (2003) Maintenance azithromycin therapy for bronchiolitis obliterans syndrome: results of a pilot study. Am J Respir Crit Care Med 168: 121125.

34. Maurer JR, Tullis DE, Grossman RF, Vellend H, Winton TL, et al. (1992) Infectious complications following isolated lung transplantation. Chest 101: 1056-1059.

35. Wierup P, Haraldsson A, Nilsson F, Pierre L, Schersten H, et al. (2006) Ex vivo evaluation of nonacceptable donor lungs. Ann Thorac Surg 81: 460-466.

36. Cypel M, Yeung JC, Liu M, Anraku M, Chen F, et al. (2011) Normothermic ex vivo lung perfusion in clinical lung transplantation. N Engl J Med 364: 1431-1440.

37. Cypel M, Liu M, Rubacha M, Yeung JC, Hirayama S, et al. (2009) Functional repair of human donor lungs by IL-10 gene therapy. Sci Transl Med 1: 4 ra9. 